\title{
microvascular networks
}

4 Nicole L. Jacobsen ${ }^{1}$, Charles E. Norton ${ }^{1}$, Rebecca L. Shaw ${ }^{1}$, DDW Cornelison ${ }^{2,}{ }^{3}$, Steven

5 S. Segal ${ }^{1,4}$.

$7 \quad{ }^{1}$ Medical Pharmacology and Physiology, ${ }^{2}$ Biological Sciences, ${ }^{3}$ Christopher S. Bond Life

8 Sciences Center, ${ }^{4}$ Dalton Cardiovascular Research Center; University of Missouri,

9 Columbia, MO 65212

11 Running Head: Capillary network remodeling during skeletal muscle regeneration

13 Correspondence:

14 Steven S. Segal, PhD

15 University of Missouri

16 Medical Pharmacology and Physiology

17 MA415 Medical Sciences Building

181 Hospital Drive

19 Columbia, MO 65212

20 Phone: (573) 882-2553

21 Email: segalss@health.missouri.edu

22

23 Keywords: capillaries, microcirculation, myofiber, skeletal muscle regeneration 


\section{Abstract}

Myofibers regenerate following injury, however the microvasculature must also

26 recover to restore skeletal muscle function. We aimed to define the nature of

27 microvascular damage and repair during skeletal muscle injury and regeneration induced

28 by $\mathrm{BaCl}_{2}$. To test the hypothesis that microvascular disruption occurred secondary to

29 myofiber injury in mice, isolated microvessels were exposed to $\mathrm{BaCl}_{2}$ or the myotoxin was

30 injected into the gluteus maximus (GM) muscle. In isolated microvessels, $\mathrm{BaCl}_{2}$

31 depolarized smooth muscle cells and endothelial cells while increasing $\left[\mathrm{Ca}^{2+}\right]_{\mathrm{i}}$, but did not

32 elicit cell death. At 1 day post injury (dpi) of the GM, capillary fragmentation coincided

33 with myofiber degeneration while arteriolar and venular networks remained intact;

34 neutrophil depletion before injury did not prevent capillary damage. Perfused capillary

35 networks reformed by 5 dpi in association with more terminal arterioles and were dilated

36 through $10 \mathrm{dpi}$; with no change in microvascular area or branch point number in

37 regenerating networks, fewer capillaries aligned with myofibers and capillary networks

38 were no longer organized into microvascular units. By $21 \mathrm{dpi}$, capillary orientation and

39 organization had nearly recovered to that in uninjured GM. We conclude that following

40 their disruption secondary to myofiber damage, capillaries regenerate as disorganized

41 networks that remodel while regenerated myofibers mature. 


\section{Introduction}

43 Skeletal muscle regeneration is an intricate process that requires the activation,

44 proliferation, and differentiation of resident stem cells called satellite cells (1). However,

45 the restoration of intact, functional muscle requires the coordinated recovery of additional

46 cell types and tissue components during myogenesis, particularly the microcirculation.

47 When compared to the well-defined molecular and cellular events of myofiber

48 degeneration and regeneration [for review, see (2)], little is known of how skeletal muscle

49 injury and regeneration affect its microvascular supply.

50 The microvasculature of skeletal muscle consists of arterioles, capillaries, and

51 venules comprising networks of branches arranged in series and in parallel (3). The

52 microcirculation delivers oxygen and nutrients to myofibers while removing cellular debris

53 and products of metabolism. To meet these physiological demands, the microcirculation

54 responds acutely by regulating local blood flow [e.g., functional hyperemia in response to

55 muscle contraction, (4)] and adapts to chronic use by modifying network morphology [e.g.,

56 increased capillarization, arteriogenesis; $(5,6)]$.

57 To study muscle injury and regeneration in mice, intramuscular injection of the

58 myotoxic agent $\mathrm{BaCl}_{2}$ induces reproducible damage while sparing sufficient satellite cells

59 to support myofiber regeneration (7). As shown in the gluteus maximus muscle (GM),

$60 \mathrm{BaCl}_{2}$ injection also damages capillaries $(8,9)$, which undergo fragmentation within 1 day

61 post injury (dpi), thereby eliminating local perfusion and solute transport. $\mathrm{BaCl}_{2}$-induced

62 myofiber death occurs through depolarization of the sarcolemma leading to $\mathrm{Ca}^{2+}$

63 overload, membrane disruption, and proteolysis (8). However, it is unknown how $\mathrm{BaCl}_{2}$

64 results in capillary fragmentation in vivo. While freeze injury and injection of snake venom 
65 toxins also disrupt capillaries accompanied by with myofiber damage (7), it is unknown

66 whether capillary fragmentation is a direct effect of the initial insult by $\mathrm{BaCl}_{2}$ or is a

67 consequence of myofiber disruption. Nor has it been determined whether arteriolar and

68 venular networks, which supply and drain capillary networks, are disrupted in the manner

69 shown for capillaries.

Ischemic injury to skeletal muscle is followed by robust angiogenesis with an

71 increase in capillary-to-myofiber ratio $(7,10)$. Following injury with $\mathrm{BaCl}_{2}$, endothelial

72 sprouts appear within 2-3 dpi, with the ensuing regeneration of capillary networks

73 restoring local perfusion by $5 \mathrm{dpi}(8,9)$. At this time, arteriolar networks are abnormally

74 dilated, with recovery of blood flow control (vasomotor tone, dilation, and constriction)

75 occurring by $21 \mathrm{dpi}$ in the mouse GM as regenerating myofibers mature (8). Nevertheless,

76 the cellular dynamics of revascularization and microvascular remodeling during myofiber

77 regeneration are poorly understood. In this study we tested the hypotheses that 1) $\mathrm{BaCl}_{2}$

78 induces death of microvascular endothelial cells (ECs) and smooth muscle cells (SMCs)

79 by triggering $\mathrm{Ca}^{2+}$ overload; and 2) capillaries proliferate during early regeneration with 80 networks remodeling as regenerating myofibers mature.

82 Results

83 Previous studies evaluating microvascular injury did not resolve whether damage

84 and loss of perfusion were a direct effect of $\mathrm{BaCl}_{2}$ on vascular cells or was secondary to

85 disruption of myofibers and leukocyte infiltration (7-9). Therefore, to evaluate the effect of

$86 \mathrm{BaCl}_{2}$ on microvascular ECs and SMCs independent of surrounding myofibers or

87 inflammation, superior epigastric arteries (SEAs) having a single layer of each cell type 
88 were isolated and exposed to $\mathrm{BaCl}_{2}$ in vitro. SMCs were studied in the wall of intact

89 vessels and ECs were evaluated in endothelial tubes following dissociation of SMCs (11).

$91 \mathrm{BaCl}_{2}$ induces depolarization and increases $\mathrm{Ca}^{2+}$ in SMCs causing vasoconstriction

93 from $-48 \pm 5 \mathrm{mV}$ (baseline) to $-19 \pm 2 \mathrm{mV}$ over several min (Fig 1A \& B). In endothelial

94 tubes, $\mathrm{BaCl}_{2}$ depolarized ECs from $-41 \pm 1 \mathrm{mV}$ (baseline) to $-20 \pm 2 \mathrm{mV}$ over a similar

95 time course (Fig 1B). Electrical responses plateaued in $7 \pm 1 \mathrm{~min}$.

96 In SMCs, membrane depolarization is accompanied by a rise in $\left[\mathrm{Ca}^{2+}\right]$ i through

97 activation of voltage gated (L-type) $\mathrm{Ca}^{2+}$ channels in the plasma membrane (12).

98 Corresponding to depolarization (Fig $1 \mathrm{~B}$ ), exposure to $\mathrm{BaCl}_{2}$ increased $\mathrm{SMC}\left[\mathrm{Ca}^{2+}\right]$ ( $\mathrm{Fig}$

99 1C) and constricted SEAs from $76 \pm 8 \mu \mathrm{m}$ (baseline) to $34 \pm 10 \mu \mathrm{m} \mathrm{BaCl} 2$ (Fig 1D). In the

100 absence of voltage gated $\mathrm{Ca}^{2+}$ channels in $\mathrm{ECs}$ (13), depolarization with $\mathrm{BaCl}_{2}$ had no

101 effect on EC $\left[\mathrm{Ca}^{2+}\right]_{i}$. Controls performed without $\mathrm{BaCl}_{2}$ confirmed that $\mathrm{Vm}$ and $\left[\mathrm{Ca}^{2+}\right]_{i}$ of

102 SMCs in pressurized SEAs and of ECs in endothelial tubes remained stable for the 103 duration of recordings (14-16).

$105 \mathrm{BaCl}_{2}$ does not directly cause microvascular cell death

Exposure of the mouse extensor digitorum longus (EDL) muscle to $1.2 \% \mathrm{BaCl}_{2}$

107 promptly depolarized myofibers and increased $\left[\mathrm{Ca}^{2+}\right]$, leading to disruption of the

108 sarcolemma and proteolysis culminating in cell death within $1 \mathrm{~h} \mathrm{(8).} \mathrm{We} \mathrm{questioned}$

109 whether $\mathrm{BaCl}_{2}$ affected microvascular cells in a similar manner. Contrary to our

110 hypothesis, $1 \mathrm{~h}$ exposure to $1.2 \% \mathrm{BaCl}_{2}$ was not lethal to SMCs or ECs in intact vessels 


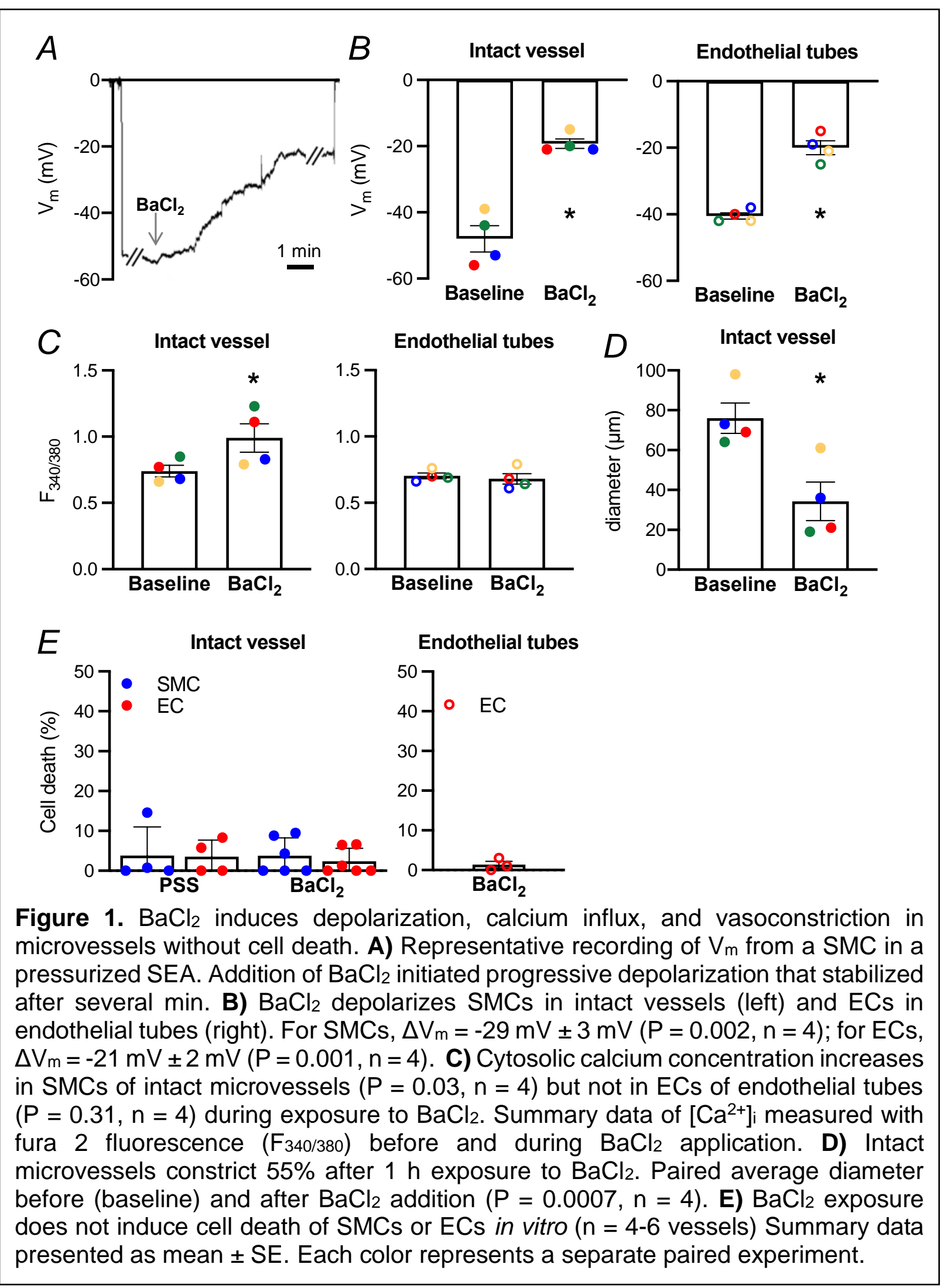


112 or to ECs in endothelial tubes (Fig 1E). Furthermore, extending $\mathrm{BaCl}_{2}$ exposure to $3 \mathrm{~h}$

113 had no further effect on EC or SMC viability $(n=3$, not shown). These data suggest that,

114 rather than a direct effect of $\mathrm{BaCl}_{2}$, the adverse microenvironment within an intact muscle

115 created by myofiber injury and degeneration leads to disruption of capillary ECs.

117 Arterioles and venules are spared from $\mathrm{BaCl}_{2}$-induced muscle injury

118 Capillaries are fragmented and perfusion is abolished within $24 \mathrm{~h}$ of muscle injury

119 (7-9). At this early timepoint, leakage of a $70 \mathrm{kDa}$ dextran from residual microvessels

120 suggested a loss of structural integrity of arterioles or venules (9). To investigate whether

121 pre- and post-capillary microvessels are also damaged by muscle injury, the GM of male

$122 \mathrm{C} 57 \mathrm{BI} / 6 \mathrm{~J}$ mice was injured by injection of $75 \mu \mathrm{L}$ of $1.2 \% \mathrm{BaCl}_{2}$ under the muscle (9).

123 Whole mount immunostaining of the GM with Myh11 labelled SMCs that encircle

124 arterioles and venules embedded within skeletal muscle. While other cell types may

125 express Myh11, they are not localized to the abluminal surface of larger caliber

126 microvessels thereby enabling positive identification of SMCs $(17,18)$. As seen for

127 isolated microvessels exposed to $\mathrm{BaCl}_{2}$ (Fig $\left.1 \mathrm{E}\right)$, the structural integrity of SMCs within

128 arteriolar networks of the GM remained essentially intact at $1 \mathrm{dpi}$, though infrequent

129 damage was observed (Fig 2). Continuous SMC coverage and arteriolar segments with

130 uniform diameter was not different at 1 dpi compared to uninjured muscle. The integrity

131 of venular segments and their SMCs was also preserved (Fig 2A \& B). Our quantitative

132 analyses therefore centered on capillary and precapillary (resistance) networks. 


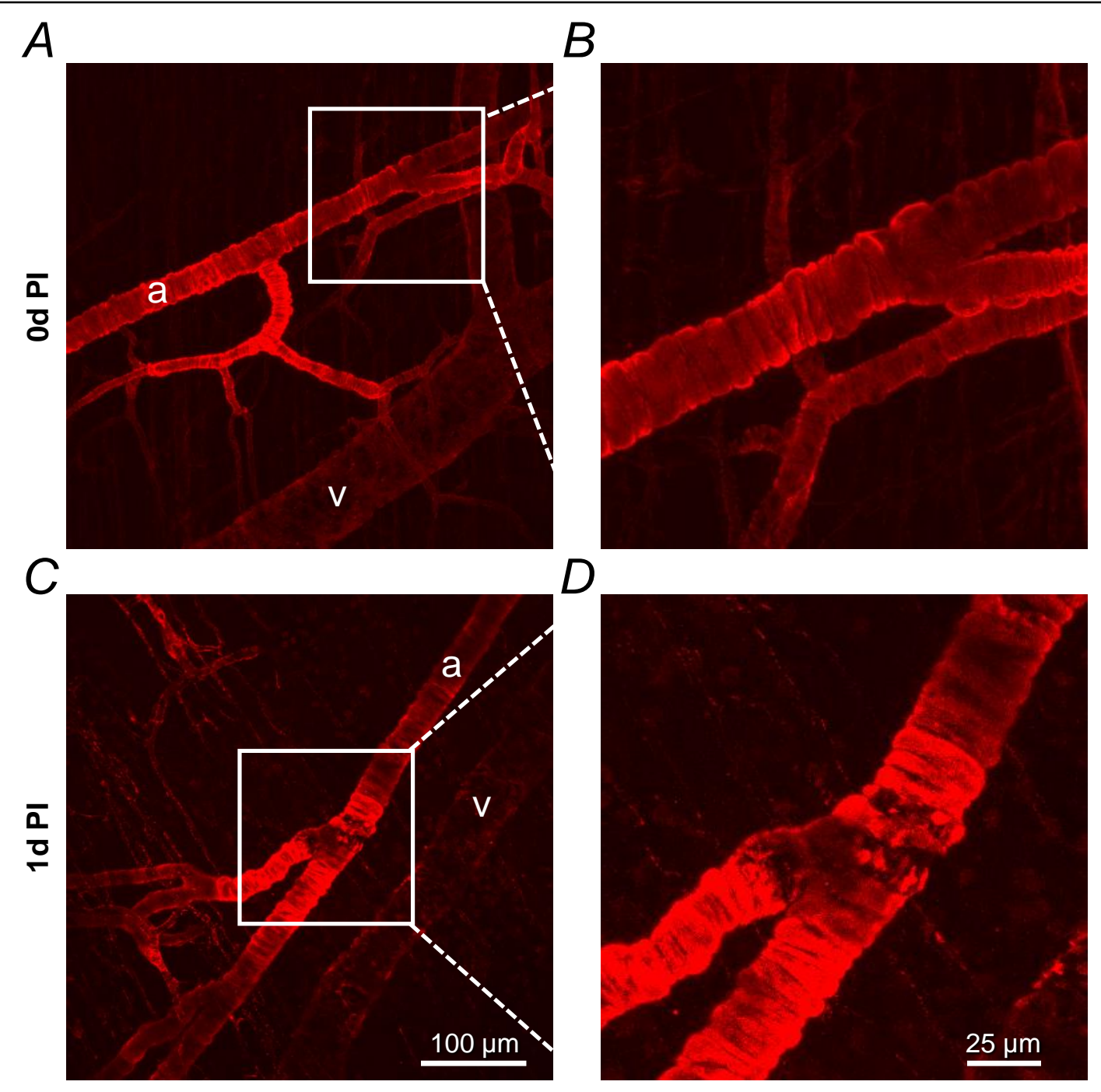

Figure 2. $\mathrm{BaCl}_{2}$ injection does not disrupt SMCs of arterioles (a) or venules (v) embedded in the GM. Representative maximum projection confocal z-stacks showing SMCs identified by Myh11 expression at (A-B) 0 dpi and (C-D) 1 dpi. Note example of rare local damage to SMCs at $1 \mathrm{dpi}$. Boxed regions within left panels are enlarged in right panels. Red = immunostaining for Myh11. Images are representative of $n=7$ tissue regions from 3 mice.

134 Role of neutrophils in $\mathrm{BaCl}_{2}$-induced capillary damage

Muscle injury initiates a stereotypical inflammatory response, with neutrophils

136 invading within 1-2 h of injury and peaking at 12-24 h post injury (19). Neutrophils release

137 cytolytic and cytotoxic molecules that may damage other resident cell types, along with 
138 cytokines that attract monocytes and macrophages to remove cellular debris (20). Given

139 the disruption of capillaries following intramuscular injection of $\mathrm{BaCl}_{2}(7,8)$ compared to

140 the integrity of $\mathrm{ECs}$ exposed to $\mathrm{BaCl}_{2}$ in vitro (Fig 1E), we tested whether invading

141 neutrophils are necessary for capillary fragmentation after $\mathrm{BaCl}_{2}$ injury. Differential blood

142 counts determined that circulating neutrophils comprised $12.6 \pm 1.8 \%(n=4)$ of white

143 blood cells in uninjured male C57BL/6J mice. At 1 dpi, neutrophils increased to $49.5 \pm$

$1443.2 \%$ of circulating white blood cells $(P<0.0001)$. Intraperitoneal injections of anti-Ly6G

$145 \mathrm{ab}$ prior to $\mathrm{BaCl}_{2}$ injury reduced circulating neutrophils at 0 dpi and at $1 \mathrm{dpi}(4.3 \pm 3.0 \%$

146 and $2.9 \pm 2.0 \%$, respectively; $P<0.0001 ; n=4$ mice per group)

147 Using an EC-specific Cre driver [Cdh5-Cre ERT2; (21)] and tamoxifen-induced

148 recombination of the Rosa26 ${ }^{\mathrm{mTmG}}$ locus to genetically label the endothelium with

149 membrane-bound eGFP (Cdh5-mTmG mice), we evaluated capillary network structure in

150 whole mount preparations of the GM. The orderly arrangement of capillary networks that

151 course along myofibers in uninjured muscle (Fig 3A) was not impacted by neutrophil

152 depletion alone. Following $\mathrm{BaCl}_{2}$ injury, capillaries were fragmented at 1 dpi (Fig 3A),

153 which explains the loss of perfusion at this time (9). While neutrophil depletion did not

154 prevent this capillary damage, there was a trend for preserving tissue area occupied by

155 capillaries (Fig 3B, $\mathrm{P}=0.28)$. As an index of capillary fragmentation with fewer pathways

156 for blood flow, the maximum continuous length of networks was decreased at $1 \mathrm{dpi}$

157 compared to $0 \mathrm{dpi}$ (Fig $3 \mathrm{C}$ ). There was a trend for the maximum continuous length to be

158 greater at 1 dpi following neutrophil depletion, but the effect was not significant (Fig 3C,

$159 P=0.18)$. Nevertheless, neutrophil-depleted mice exhibited greater capillary perfusion as

160 visualized by FITC-dextran circulating in the bloodstream (Fig 3D). 


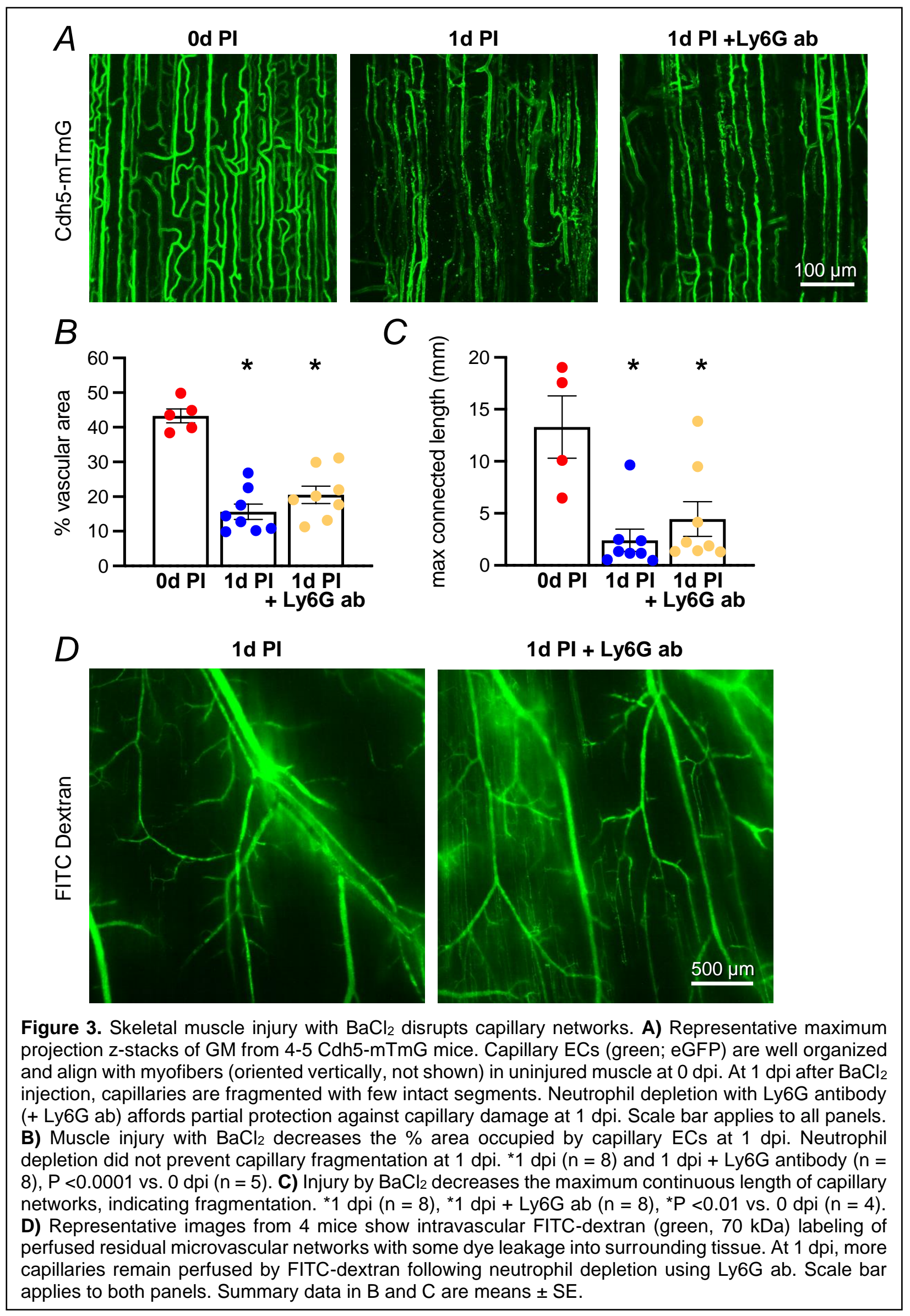


Regenerating capillary networks are dilated and disorganized

167 capillary networks appeared disorganized and dilated during their regeneration, with

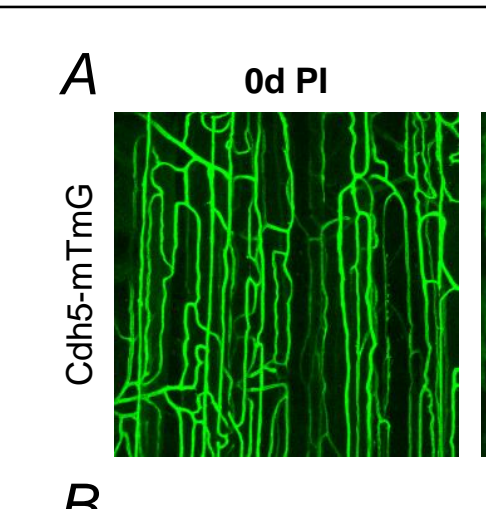

$B$

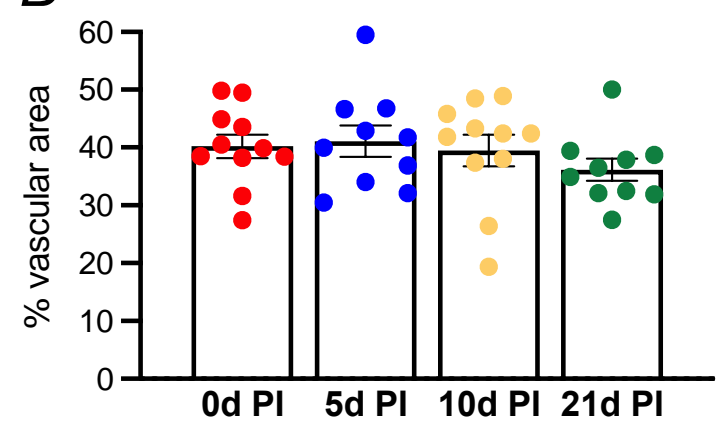

$5 d \mathrm{PI}$

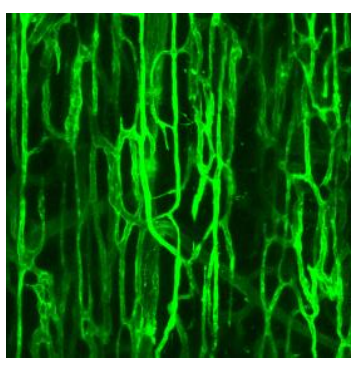

10d PI

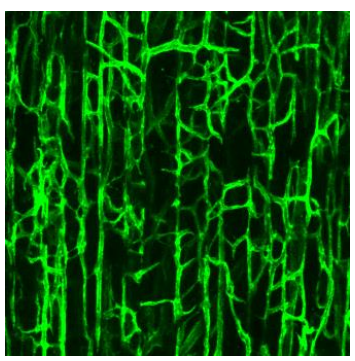

C 21d PI

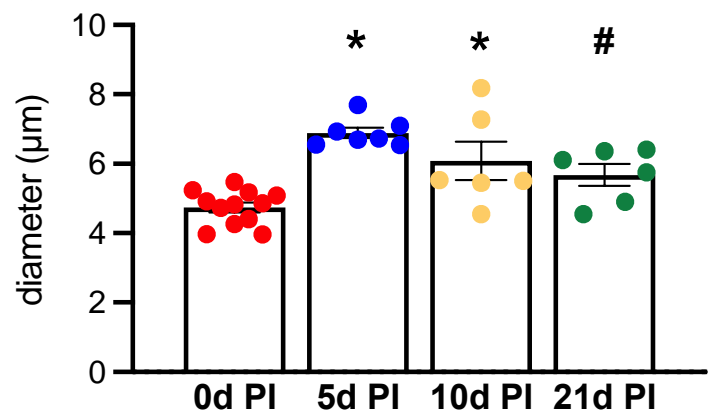

Figure 4. Regenerated capillaries are initially dilated when reperfused, but microvascular density is similar throughout regeneration. A) Maximum projections of confocal z-stacks acquired from GM of Cdh5-mTmG mice before injury and during regeneration (ECs = green; eGFP). Representative images from 4-5 mice. Scale bar applies to all panels. B) Following capillary fragmentation at $1 \mathrm{dpi}$ (see Figure $3 \mathrm{~A}$ ), the $\%$ vascular area has returned to control levels by $5 \mathrm{dpi}$ and is not different throughout regeneration ( $n=10-11$ images from 5-6 mice per timepoint). C) Capillaries are dilated at 5 and $10 \mathrm{dpi}$ but return to uninjured diameter by $21 \mathrm{dpi}(\mathrm{n}=6-12$ images per timepoint from 4 mice) ${ }^{*} \mathrm{P}<0.01 \mathrm{vs.} 0 \mathrm{dpi}$; $\mathrm{P}<0.05$ vs. 5 dpi. Summary data are means \pm SE. 
169 at $10 \mathrm{dpi}$ (Fig 4C). By $21 \mathrm{dpi}$, capillary diameter $(5.7 \pm 0.3 \mu \mathrm{m})$ was no longer significantly 170 different from uninjured controls.

171 To quantitatively examine morphological changes in regenerating capillary

172 networks, we first evaluated the number of branch points. In uninjured muscle (0 dpi),

173 there was $26 \pm 2$ branch points $/ \mathrm{mm}$ of network length and this value did not change

174 throughout regeneration (Fig 5A). However, capillary regeneration was nonuniform.

175 Poorly vascularized regions (not shown) were located adjacent to regions of high

176 angiogenic activity which often had elongating sprouts that connected with neighboring

177 capillaries to form a dense microvascular mesh (Fig 5B) that resembled a developmental

178 vascular plexus (22). Trifurcations not found in uninjured muscle were also present within

179 regenerating networks at $10 \mathrm{dpi}$, albeit with low incidence (Fig 5B).

Nascent capillaries grew in multiple directions such that fewer capillaries aligned

181 with regenerating myofibers, as documented by an orientation analysis. To calculate the

$182 \%$ of capillary segments parallel to myofibers, the distribution of their angles was plotted

183 relative to myofibers, which were oriented vertically at $0^{\circ}$ for reference and horizontal

184 defined as $-90^{\circ}$ and $+90^{\circ}$. Capillary segments in uninjured $\mathrm{GM}$ oriented within 1 standard

185 deviation of vertical were considered parallel to myofibers $\left(-5\right.$ to $\left.+5^{\circ}\right)$. This interval was

186 used as a reference for 5, 10 and $21 \mathrm{dpi}$ in Figure 5. In uninjured muscle ( $0 \mathrm{dpi}$ ), $47 \pm 3 \%$

187 of capillaries were parallel to myofibers (Fig 5 C). However, at $5 \mathrm{dpi}$, only $34 \pm 2 \%$ of

188 regenerated capillaries were parallel with myofibers; this structural disorientation 189 persisted through $10 \mathrm{dpi}$. However, by $21 \mathrm{dpi}$ the \% of capillaries orientated parallel to

190 myofibers was no longer different from 0 dpi. Capillary network disorientation was 191 manifested by the loss of identifiable microvascular units (MVUs), defined as a group of 


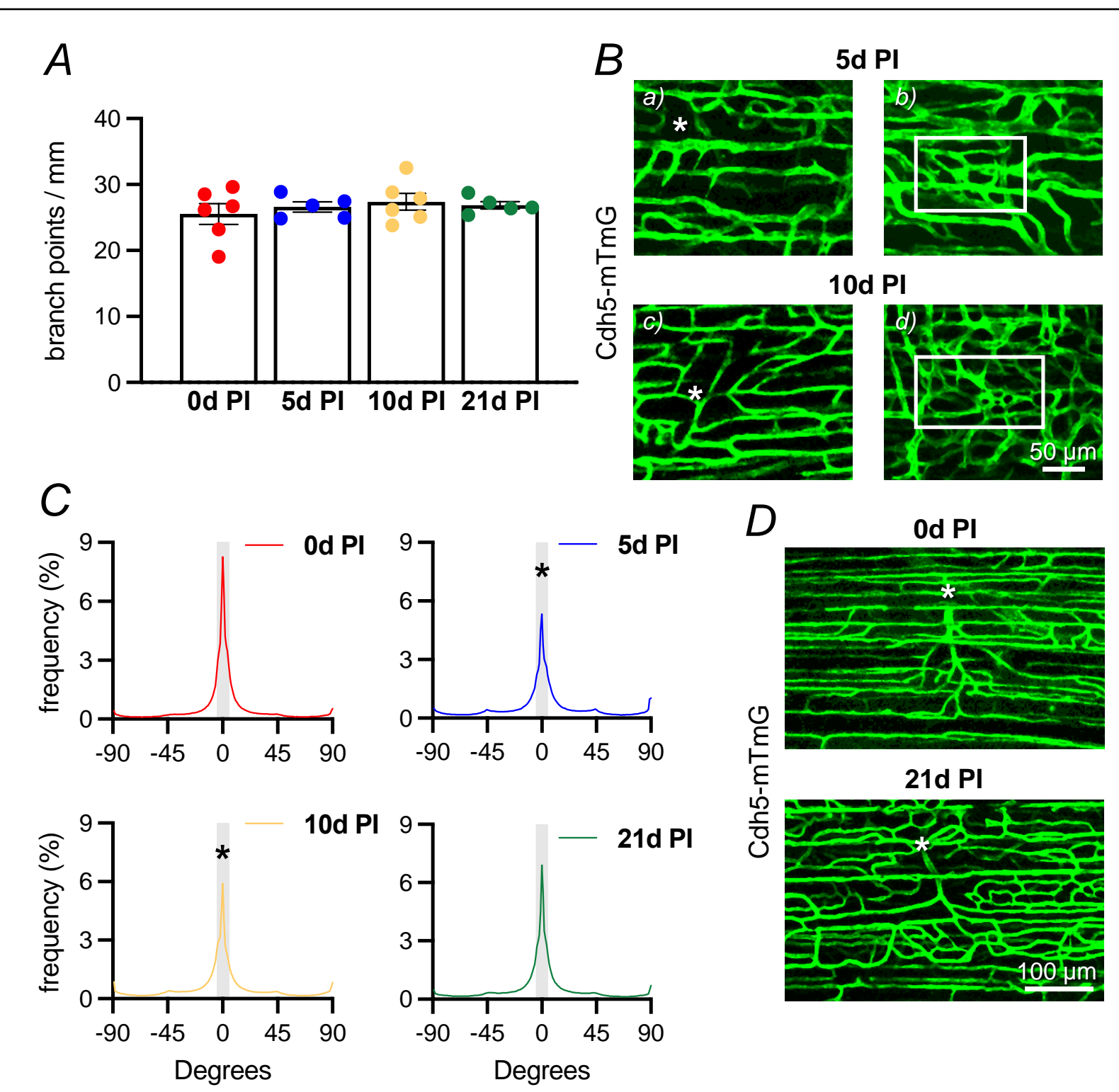

Figure 5. Regenerated capillary networks are disorganized. A) Branch point frequency (\# / total capillary vascular length, $\mathrm{mm}$ ) is not different throughout regeneration $(\mathrm{n}=5-6$ images from 4-5 mice). Summary data are means \pm SE. B) Confocal z-stacks of GM from Cdh5-mTmG mice highlighting unique capillary structures during regeneration. At 5 dpi injury, a) sprouts elongate towards adjacent capillaries creating b) a dense mesh (within box). By $10 \mathrm{dpi}, c$ ) trifurcations $\left(^{*}\right)$ are present, which are not found in uninjured muscle. In addition, $d$ ) multiple anastomoses create plexus-like structures (box) similar to those occurring during development (ECs = green; eGFP). Scale bar applies to all panels. C) Regenerated capillaries are less well aligned with myofibers (oriented vertically at $0^{\circ}$ ) at $5 \mathrm{~d}$ and $10 \mathrm{dpi}$ compared to uninjured controls ( $0 \mathrm{dpi}$ ). By $21 \mathrm{dpi}$, capillaries have remodeled such that their orientation is no longer different from 0 dpi ( $n=5-6$ per time point from $4-5$ mice, ${ }^{*} P<0.01$ vs. 0 dpi). Grey bar: \pm 1 standard deviation of Gaussian fit at 0 dpi for capillaries oriented parallel to myofibers ( -5 to $+5^{\circ}$ ) superimposed for each timepoint for reference. D) A microvascular unit (MVU) constitutes a terminal arteriole $\left(^{*}\right)$ and the capillaries it supplies in both directions. MVUs are readily identified at 0 dpi but cannot be resolved before 21 dpi because of disoriented segments (e.g, panels in $B$ ). 
193 capillaries supplied by a common terminal arteriole (23). Restoration of organized MVUs

194 characteristic of uninjured skeletal muscle was not apparent until $21 \mathrm{dpi}$ (Fig 5D), which

195 corresponds with maturation of regenerating myofibers in the mouse $\mathrm{GM}$ following $\mathrm{BaCl}_{2}$

196 injury (9).

198 Terminal arterioles remodel during muscle regeneration

200 capillaries and MVUs (Fig 5), we questioned whether the architecture of arteriolar

201 networks underwent remodeling during regeneration. At criterion timepoints, the GM

202 vasculature of male C57BL/6J mice was manually traced from the inferior gluteal artery

203 (feed artery) to terminal arterioles (Fig 6). Resulting traces included intra-network

204 anastomoses and collateral connections to arterioles originating from the superior gluteal

205 artery.

$206 \quad$ Uninjured muscle contained $452 \pm 78$ microvessel segments (Fig 7A). During 207 regeneration, the total \# of segments was not different compared to $0 \mathrm{dpi}$; the total 208 vascular length was also not different at the timepoints studied. However, when 209 categorized by microvessel diameter, the \# of arterioles 5-10 $\mu \mathrm{m}$ in diameter (i.e., terminal 210 arterioles) increased at $5 \mathrm{dpi}$ compared to $0 \mathrm{dpi}$ and remained elevated through $21 \mathrm{dpi}$

211 (Fig 7B). The corresponding cumulative vascular length of the smallest arterioles was

212 also increased at 5 dpi vs. 0 dpi indicating proliferation of terminal arterioles (Fig 7C). In

213 addition, more anastomoses were present in microvascular networks at 5 dpi than other

214 timepoints (Fig 7D), reflecting the rapid angiogenesis during the early stages of 215 regeneration. 


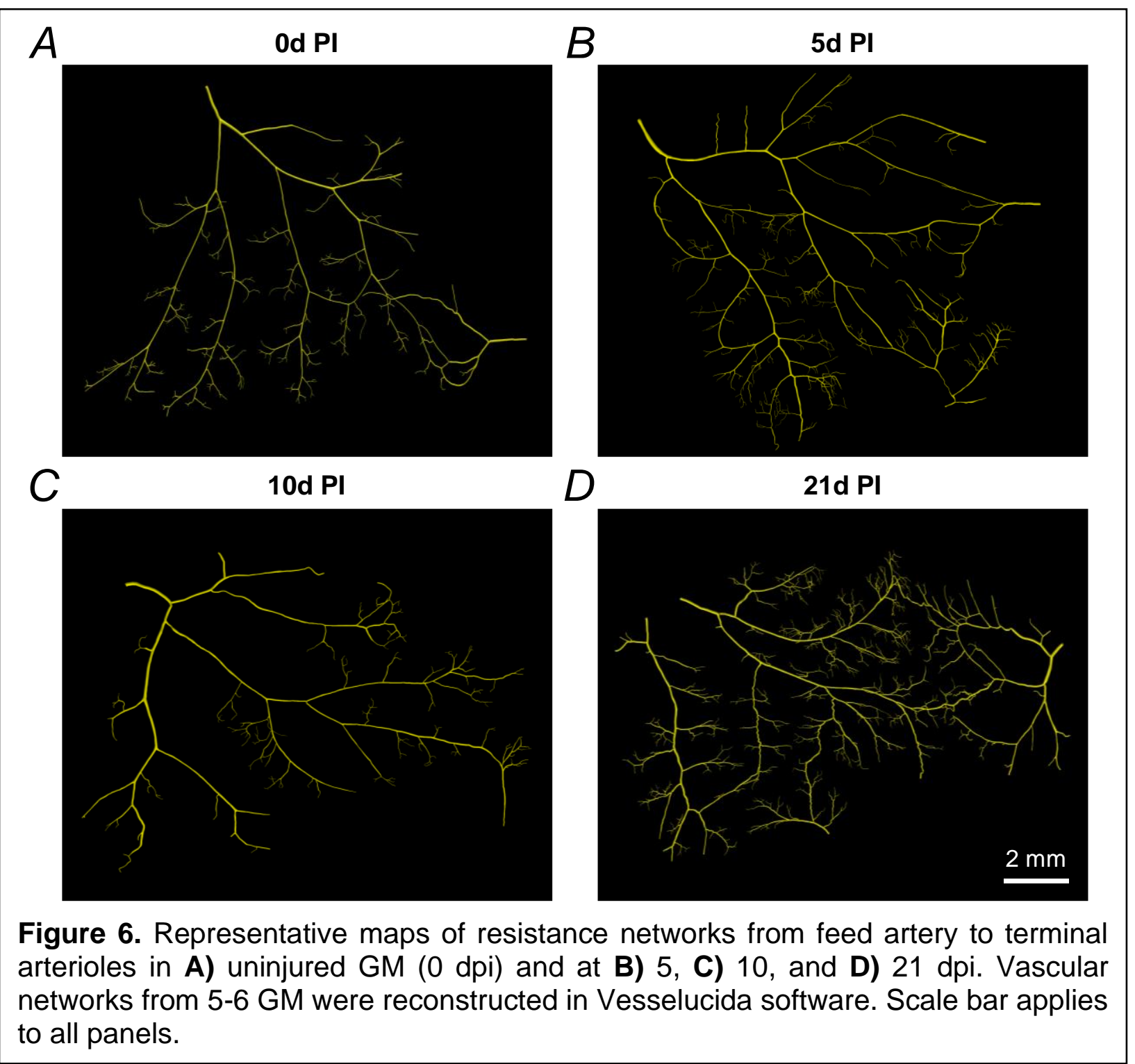

\section{Discussion}

Apart from myofibers, microvascular cells represent the largest cell population in

219 healthy adult skeletal muscle (24). This relationship underscores the reliance of skeletal

220 muscle on a robust microvascular supply to support the metabolic demands of myofibers.

221 Because myofibers depend upon their microvascular supply for survival, understanding 


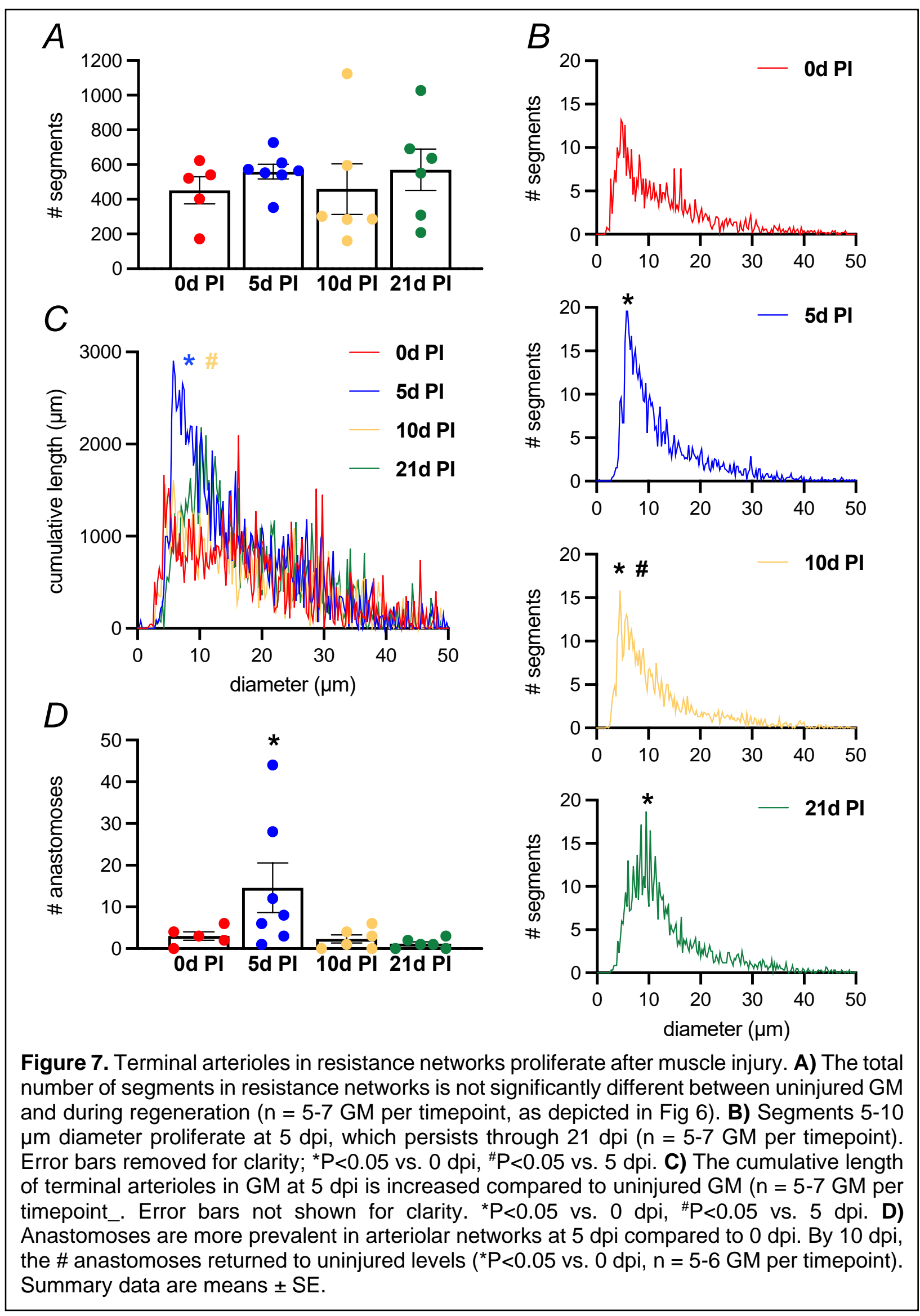


223 how microvascular cells respond after skeletal muscle injury and during regeneration is

224 integral to the development of therapies targeted to promote muscle regeneration.

226 Microvascular cell damage after muscle injury

227 We showed that $\mathrm{BaCl}_{2}$ induces depolarization of SMCs and ECs (Fig $1 \mathrm{~A} \& \mathrm{~B}$ ),

228 consistent with its action as a broad-spectrum $\mathrm{K}^{+}$channel inhibitor $(25,26)$. However, the

229 consequences of such an effect differ between microvascular cells and myofibers. In

230 myofibers, $\mathrm{BaCl}_{2}$-induced depolarization is accompanied by a rise in $\left[\mathrm{Ca}^{2+}\right]$ i resulting in

231 proteolysis, membrane disruption, and cell death within $1 \mathrm{~h}(8)$. Elevation of $\left[\mathrm{Ca}^{2+}\right]_{\mathrm{i}}$ can

232 increase mitochondrial $\mathrm{Ca}^{2+}$ content to trigger cytochrome $\mathrm{C}$ release and intrinsic

233 apoptosis (27). For SMCs exposed to the same conditions, membrane depolarization also

234 increased $\left[\mathrm{Ca}^{2+}\right]$, which led to vasoconstriction (Fig 1D), as seen in rabbit aorta (28).

235 However, since cell death did not occur after the same duration of exposure (or even

236 when extended to $3 \mathrm{~h}$ ), the present findings indicate that either longer exposure to $\mathrm{BaCl}_{2}$

237 is necessary (which is unlikely given the equal probability for $\mathrm{BaCl}_{2}$ diffusion into both cell

238 types) or that the rise in $\left[\mathrm{Ca}^{2+}\right]_{i}$ was not sufficient to induce SMC death. Finding negligible

239 disruption of arteriolar or venular SMCs at $1 \mathrm{dpi}$ (Fig 2) when myofibers have degenerated

240 supports the latter explanation. We suggest that varying amounts of mitochondria,

241 expression of different L-type $\mathrm{Ca}^{2+}$ channel isoforms, the ability for the

242 sarcoplasmic/endoplasmic reticulum to sequester $\mathrm{Ca}^{2+}$ without dysfunction, or expression

243 of pro-apoptotic proteins may explain the difference in cell death between myofibers and

244 microvascular SMCs exposed to $\mathrm{BaCl}_{2}(29,30)$. 
When recording from ECs in endothelial tubes, depolarization occurred without an increase in $\left[\mathrm{Ca}^{2+}\right]_{i}(\mathrm{Fig} 1 \mathrm{~B} \& \mathrm{C})$, which is consistent with their lack of voltage operated $\mathrm{Ca}^{2+}$

247 channels in the plasma membrane (13). Furthermore, no cell death was evident in

248 endothelial tubes exposed to $\mathrm{BaCl}_{2}$ (Fig 1E). That ECs comprising capillaries are

249 damaged following $\mathrm{BaCl}_{2}$ injection in vivo [Fig $3 \mathrm{~A},(7,8)$ ], but ECs directly exposed to

$250 \mathrm{BaCl}_{2}$ in vitro are not (Fig $\left.1 \mathrm{E}\right)$, suggests that $\mathrm{ECs}$ in arteriolar and venular networks may

251 be protected by SMCs in vivo and that the otherwise exposed capillary ECs are injured

252 secondary to myofiber degeneration from $\mathrm{BaCl}_{2}$ exposure. Upon exposure to $\mathrm{BaCl}_{2}$, 253 resting force of the mouse EDL muscle increases $\sim 40 \%$ over 15 min, which then returns

254 to baseline as proteolysis disrupts the integrity of contractile proteins (8). Given that

255 evidence of capillary damage is not apparent during this time, the present data imply that

256 skeletal muscle tissue degeneration induces capillary fragmentation hours after injury,

257 rather than as a consequence of persistent myofiber contraction.

259 neutrophils that generate pro-inflammatory cytokines, chemokines, and reactive oxygen 260 species which exacerbate tissue damage (20). While neutrophil depletion prior to $\mathrm{BaCl}_{2}$

261 injection did not prevent capillary damage at $1 \mathrm{dpi}($ Fig 3A \& B), more capillaries remained 262 perfused when compared to mice in which neutrophils were not depleted (Fig 3D). This 263 outcome suggests that while neutrophil activity contributes to capillary damage, additional

264 mechanisms lead to EC death when skeletal muscle is injured. Candidates include toxic 265 substances released from degenerating myofibers, reactive oxygen species, calpain266 dependent protein degradation, recruitment of proinflammatory cells including monocytes 267 and macrophages (20, 31-34). 
268

269

270

271

272

273

274

275

276

277

278

279

280

281

282

283

284

285

286

287 repulsive signals in the microenvironment. Stalk cells trail tip cells and proliferate to 288 elongate nascent capillaries such that by 5 dpi, capillary networks have reformed (Fig 4A) 289 and perfusion is restored (9). While others have reported no change or even a reduction

290 in the diameter of capillaries during the early stages of muscle regeneration (7), we

\section{Restoration of capillary networks during muscle regeneration}

Previous studies investigating capillarity during regeneration evaluated muscle cross sections $(7,35)$ and therefore cannot address the dynamics of microvascular network organization. Cross sections are inherently biased towards vessels oriented parallel to myofibers (36), which compromises the resolution of transverse microvessels and anastomoses. Moreover, studies that have examined the intact microcirculation during skeletal muscle regeneration have focused on hindlimb muscles such as the tibialis anterior (7) and EDL (10), which restricts observations to the superficial portion of the muscle due to the thickness of the tissue. While capillaries, terminal arterioles, and collecting venules can be observed, proximal resistance networks reside deeper in the muscle. To overcome these limitations, we evaluated microvascular regeneration in the GM, a thin, flat skeletal muscle well suited to high resolution imaging and analysis of entire microvascular networks (9).

Triggered by the release of such growth factors as VEGF, FGF, and IGF-1 from the hypoxic milieu (37), nascent capillaries sprout and elongate from surviving microvessel fragments at 2-3 dpi $(7,8)$. These regions of angiogenic activity within the tissue highlight the selective roles of individual ECs during angiogenesis. As shown during development, endothelial tip and stalk cells are selected after stimulation by VEGF and Notch signaling (38). Tip cells guide capillary sprouts as they sense attractive and 
291 observed a $\sim 30 \%$ increase in capillary diameter at 5 and $10 \mathrm{dpi}$ (Fig 4B). Vasodilation is

292 one of the earliest steps in both physiological and pathological angiogenesis (39). That

293 resistance arterioles are also dilated at this time (9) suggests that regenerating skeletal

294 muscle requires elevated blood flow afforded by a dilated microvasculature providing

295 ample nutrients for cellular regeneration. Capillary dilation may reflect aberrant coverage

296 by mural cells (pericytes) or dysregulated inter- and intracellular signaling (40-42).

298 regions with extensive damage that are poorly perfused or avascular at $5 \mathrm{dpi}$, implying

299 that microvascular regeneration after skeletal muscle injury is asynchronous between

300 neighboring regions of tissue. Heterogeneity amongst ECs exists between vascular beds,

301 microvessels, and even along the length of a single microvessel in healthy skeletal

302 muscle $(43,44)$. Corresponding differences in gene expression and nuances in EC

303 function may explain the asynchronous regenerative response of the microvasculature.

304 In response to tissue hypoxia, angiogenesis occurs primarily in areas containing glycolytic

305 (type II) myofibers $(45,46)$, suggesting that diffusion distances for $\mathrm{O}_{2}$ and metabolites

306 affect the angiogenic response. That the GM is a muscle comprised of mixed fiber type

307 (47) is consistent with the observed heterogeneity in angiogenesis during regeneration of

308 the GM.

In addition to the density of capillary networks, optimal distribution of capillaries is

310 crucial for adequate muscle oxygenation. Heterogenous capillary spacing negatively

311 impacts muscle oxygenation due to local increases in diffusion distances $(48,49)$.

312 Microvascular structures resembling a developmental vascular plexus were present

313 throughout the GM at 5 and $10 \mathrm{dpi}$ (Fig 5B), with disorganized capillary networks 
314 containing abnormal branching (e.g., trifurcations) and more segments that were not

315 aligned with regenerating myofibers (Fig 5C). Similar abnormal microvascular

316 morphogenesis has been described after grafting the hamster tibialis anterior muscle (50)

317 or ischemic injury to mouse EDL muscle (10).

318 A microvascular unit constitutes a terminal arteriole and the group of capillaries it

319 supplies (3). Following injury of the GM, the organization of capillaries into discernable

320 MVUs apparent in uninjured muscle was not identifiable until $21 \mathrm{dpi}$ (Fig 5D), the timepoint

321 which coincides with the recovery of blood flow control in the resistance vasculature of

322 the $\mathrm{GM}$ following $\mathrm{BaCl}_{2}$ injury (9). In uninjured healthy skeletal muscle, terminal arterioles

323 are oriented obliquely to myofibers, whereas capillaries primarily run parallel with

324 myofibers. When a terminal arteriole constricts or dilates, flow through all capillaries it

325 supplies diminishes or increases, respectively. We anticipated that nascent microvessels

326 would repopulate residual basement membranes (51-54) following microvascular

327 damage from skeletal muscle injury $(7,55)$. In contrast to the organization of MVUs in

328 healthy muscle, regenerated microvascular networks were less aligned with myofibers,

329 contained irregular structures, and required $21 \mathrm{dpi}$ to approximate normal structure. This

330 delay in reorganization implies that nascent capillaries did not regrow along basement

331 membranes of old microvessels. We suggest that these structural abnormalities in

332 capillary networks contribute to nonuniform perfusion during the early stages of myofiber

333 regeneration. The persistence of arteriolar dilation during this time maintains capillary

334 perfusion, which may help compensate for limitations imposed by aberrant capillary

335 network organization. 


\section{7}

338

339

340

341

342

343

344 increase in the number of anastomoses in arteriolar networks at $5 \mathrm{dpi}$ (Fig 7D). These

345 direct connections ensure redundancy in blood flow paths to limit underperfusion in

346 addition to promoting the maximum delivery and removal of blood to regenerating tissue

347 before local blood flow control recovers. While the origin of new arterioles in

348 microvascular networks during regeneration remains incompletely understood, nascent

349 capillaries may become "arterialized" by recruiting mural cells (57). Together, the data

350 suggest that the repair, recovery, and maintenance of new myofibers requires a robust

351 supply of oxygen and nutrients from the regenerating microcirculation preceding the

352 recovery of blood flow regulation.

353

\section{Conclusion}

355

356 close association with myofibers, providing oxygen and nutrients while removing

357 metabolic byproducts. The present study shows that capillaries, but not SMCs or ECs of

358 larger microvessels, are disrupted by the microenvironment created by degenerating

359 myofibers. When perfusion is restored, nascent capillary networks are dilated, 
360 disorganized, and associated with more terminal arterioles. These early morphological 361 adaptations may compensate for lack of blood flow regulation during myofiber

362 regeneration (9). Reorganization of capillaries and terminal arterioles into MVUs at $21 \mathrm{dpi}$

363 coincides with restoration of the number myofibers, their cross-sectional area, and the

364 recovery of blood flow regulation in resistance networks. Understanding how

365 microvascular structure and function are restored following skeletal muscle injury 366 provides new insight for developing therapeutic interventions for the treatment of acute

367 muscle trauma in the adult.

369 Materials and Methods

370 Ethical approval

371 All procedures were approved by the Animal Care and Use Committee at the

372 University of Missouri (protocol \#10050) and were performed in accordance with the

373 National Research Council's Guide for the Care and Use of Laboratory Animals and the

374 animal ethics checklist of this journal.

375

376 Animal care and use

377 Male C57BI/6J mice were purchased from Jackson Laboratory (Bar Harbor, ME, 378 USA) at $\sim 14$ weeks of age and acclimated at the University of Missouri animal care 379 facilities at least 1 week prior to study. Male Cdh5-mTmG mice [cross of VE-cadherin380 CreERT2 mice (21) (gifted from Dr. Luisa Iruela-Arispe) and Rosa26-mTmG mice 381 (\#007676, Jackson Laboratory); both on C57BL/6 background] were bred and housed in 382 animal care facilities of the University of Missouri. Mice were studied at $\sim 4$ months of age. 
383 Cre recombination for membrane-bound eGFP expression in ECs was induced through

384 intraperitoneal injection of $100 \mu \mathrm{g}$ tamoxifen $(1 \mathrm{mg} / 100 \mu \mathrm{L}$ in peanut oil; \#T5648, Sigma-

385 Aldrich; St. Louis, MO, USA) on 3 consecutive days with at least 1 week allowed after the

386 first injection prior to study. All mice were maintained under a 12:12 $\mathrm{h}$ light/dark cycle at

$38722-24^{\circ} \mathrm{C}$ with fresh food and water ad libitum. To control for an order effect, criterion time

388 points and treatment status were randomized.

Preparation of isolated microvessels and endothelial tubes

On the morning of an experiment, a male $\mathrm{C} 57 \mathrm{BI} / 6 \mathrm{~J}$ mouse was anesthetized

392 [ketamine $(100 \mathrm{mg} / \mathrm{kg})+$ xylazine $(10 \mathrm{mg} / \mathrm{kg})$ in sterile saline; intraperitoneal injection],

393 abdominal fur was shaved, and a midline incision through the skin was made from the

394 sternum to the pubis. The abdominal muscles were exposed, removed bilaterally, and

395 placed in a dissection chamber containing chilled, nominally $\mathrm{Ca}^{2+}$ free physiological salt 396 solution (PSS, pH 7.4) containing (in mM): $140 \mathrm{NaCl}$ (Fisher Scientific; Pittsburgh, PA, 397 USA), $5 \mathrm{KCl}$ (Fisher), $1 \mathrm{MgCl}_{2}$ (Sigma), $10 \mathrm{HEPES}$ (Sigma), and 10 glucose (Fisher); 398 standard PSS also contained $2 \mathrm{mM} \mathrm{CaCl}_{2}$ (Fisher). Muscles were pinned as a flat sheet 399 onto transparent silicone rubber (Sylgard 184; Dow Corning; Midland, MI, USA). While 400 viewing through a stereomicroscope, an unbranched segment of the superior epigastric 401 artery [SEA; length, $\sim 2 \mathrm{~mm}$; diameter, $\sim 150 \mu \mathrm{m}$; comprised of a single smooth muscle 402 cell (SMC) layer surrounding the endothelial cell (EC) monolayer] was dissected from the 403 surrounding tissue. Following isolation, an SEA was transferred to a tissue chamber 404 (\#RC27-N; Warner Instruments; Hamden, CT) for cannulation. The tissue chamber was 405 secured in a platform with micromanipulators (MT-XYZ; Siskiyou Corp; Grants Pass, OR, 
406 USA) positioned at each end that held heat-polished cannulation micropipettes (external 407 diameter, $\sim 100 \mu \mathrm{m})$. The SEA was cannulated at each end and secured with suture. The 408 vessel preparation was transferred to the stage of a Nikon E600FN microscope (Tokyo, 409 Japan) mounted on a vibration isolation table (TMC Vibration Control; Peabody, MA, 410 USA). The vessel was pressurized to $100 \mathrm{~cm} \mathrm{H} 2 \mathrm{O}(\sim 75 \mathrm{mmHg})$, maintained at $37^{\circ} \mathrm{C}$, 411 superfused at $3 \mathrm{~mL} / \mathrm{min}$ with standard PSS, and allowed to equilibrate for $15 \mathrm{~min}$ before 412 experimentation.

413 To isolate intact endothelial tubes, an SEA segment (length, $\sim 1 \mathrm{~mm}$, diameter, 60 $414 \mu \mathrm{m}$ ) was placed into a round bottom test tube containing $0.62 \mathrm{mg} / \mathrm{mL}$ papain (\#P4762, 415 Sigma), $1 \mathrm{mg} / \mathrm{mL}$ dithioerythritol (\#D8255, Sigma), and $1.5 \mathrm{mg} / \mathrm{mL}$ collagenase (\#C8051, 416 Sigma) in PSS and incubated for $30 \mathrm{~min}$ at $34^{\circ} \mathrm{C}$ (11). The vessel segment was

417 transferred to the tissue chamber and gently triturated to remove the SMCs by aspirating 418 and ejecting the segment through borosilicate glass capillary tubes that were heat 419 polished at one end (tip internal diameter, $\sim 80 \mu \mathrm{m}$ ). Following dissociation of SMCs 420 (confirmed by visual inspection at 200X magnification), the endothelial tube was secured 421 against the bottom of the chamber with blunt fire-polished micropipettes held in the 422 micromanipulators. The preparation was secured on an inverted microscope (\#TS100, 423 Nikon) mounted on a vibration isolation table (TMC Vibration Control; Peabody, MA, 424 USA). The endothelial tube was maintained at $33^{\circ} \mathrm{C}$, superfused at $3 \mathrm{~mL} / \mathrm{min}$ with 425 standard PSS, and equilibrated for $15 \mathrm{~min}$ before experimentation. 
Membrane potential $\left(\mathrm{V}_{\mathrm{m}}\right)$ of SMCs (intact pressurized SEA) or ECs (freshly

429 isolated endothelial tube) was recorded with an Axoclamp amplifier (2B; Molecular

430 Devices; Sunnyvale, CA, USA) using micropipettes pulled (P-97; Sutter) from glass

431 capillary tubes (\#GC100F-10; Warner; Hamden, CT, USA) and backfilled with $2 \mathrm{M} \mathrm{KCl}$

432 (tip resistance, $\sim 150 \mathrm{M} \Omega$ ). A Ag/AgCl pellet was placed in effluent standard PSS for the

433 reference electrode. The output of the amplifier was connected to a data acquisition

434 system (Digidata 1322A; Molecular Devices) and an audible baseline monitor (ABM-3;

435 World Precision Instruments; Sarasota, FL, USA). Data were recorded at $1000 \mathrm{~Hz}$ using

436 Axoscope 10.1 software (Molecular Devices) on a personal computer. Successful

437 impalements were indicated by sharp negative deflection of $V_{m}$, stable $V_{m}>1$ min, and

438 prompt return to $0 \mathrm{mV}$ upon withdrawal of the electrode. Once a cell was impaled, $\mathrm{V}_{\mathrm{m}}$ was

439 recorded for at least $5 \mathrm{~min}$ to establish a stable baseline. The superfusion solution was

440 then changed to PSS containing $1.2 \% \mathrm{BaCl}_{2}$ until the $\mathrm{V}_{\mathrm{m}}$ response had stabilized ( 10

$441 \mathrm{~min})$. Each experiment represents paired data under resting baseline conditions and

442 when stabilized during with $\mathrm{BaCl}_{2}$ treatment for an intact vessel (SMCs) or endothelial

443 tube (ECs) from a separate mouse.

444

445 Calcium photometry

446 A cannulated, pressurized SEA was secured in a tissue chamber and placed on

447 an inverted microscope. The vessel was superfused $(3 \mathrm{~mL} / \mathrm{min})$ at $37^{\circ} \mathrm{C}$ for $20 \mathrm{~min}$ with

448 standard PSS, then incubated in a static bath containing fura 2-AM dye (\#F14185,

449 Fisher). The dye was dissolved in DMSO, diluted to $1 \mu \mathrm{M}$ in standard PSS, and added to

450 the tissue chamber for 40 min. Superfusion with standard PSS was then resumed for 20 
451 min to wash out excess dye. Fura 2 fluorescence was used to evaluate $\left[\mathrm{Ca}^{2+}\right]_{i}$ by

452 alternatively exciting the preparation at $340 \mathrm{~nm}$ and $380 \mathrm{~nm}$ while recording emissions at

$453510 \mathrm{~nm}$ through a 20X objective [Nikon Fluor20, numerical aperture (NA) $=0.45$ ] using

454 IonWizard 6.3 software (IonOptix, Milford, MA). After fluorescence and vessel diameter

455 were recorded under baseline conditions, $1.2 \% \mathrm{BaCl}_{2}$ was added to the superfusion

456 solution. Intracellular $\mathrm{Ca}^{2+}$ signals and vessel diameter were measured over $30 \mathrm{~min}$ of

$457 \mathrm{BaCl}_{2}$ exposure. Under these conditions (dye loaded from the bath), the $\left[\mathrm{Ca}^{2+}\right]_{i}$ signal

458 primarily originates from SMCs (16).

459 To measure $\left[\mathrm{Ca}^{2+}\right]_{\mathrm{i}}$ in ECs, an endothelial tube was incubated for 30 min with fura

460 2-AM dye in a static bath and then washed for $20 \mathrm{~min}$ with standard PSS. To maintain

461 their integrity, these preparations were studied at $33^{\circ} \mathrm{C}(58)$. After baseline fluorescence

462 was recorded, $\mathrm{Ca}^{2+}$ signals $\left(\mathrm{F}_{340} / \mathrm{F}_{380}\right)$ were measured during $30 \mathrm{~min}$ of exposure to $1.2 \%$

$463 \mathrm{BaCl}_{2}$ in standard PSS; responses typically stabilized within 10 min.

$464 \quad$ Each experiment represents paired data under resting baseline conditions and

465 during stabilization of the response to $\mathrm{BaCl}_{2}$ treatment for an intact vessel or endothelial

466 tube from a separate mouse.

467

468 Cell death

469 Following equilibration in standard PSS, the superfusion solution was changed to

470 PSS containing 1.2\% $\mathrm{BaCl}_{2}$. After preparations were exposed to $\mathrm{BaCl}_{2}$ for $1 \mathrm{~h}$ [which kills

$471>90 \%$ myofibers, (8)], superfusion with standard PSS was restored. The membrane

472 permeant nuclear dye Hoechst 33342 (1 $\mu \mathrm{M}$; \#H1399, Fisher) was used to identify nuclei

473 of all cells and propidium iodide ( $2 \mu \mathrm{M}$, \#P4170, Sigma) to identify nuclei in dead and 
474 dying cells $(14,15)$. Following $\mathrm{BaCl}_{2}$ exposure, respective nuclear dyes (in standard PSS)

475 were perfused through the lumen of a cannulated SEA $(0.1 \mathrm{~mL} / \mathrm{min})$ or superfused over

476 the surface of an endothelial tube for $10 \mathrm{~min}$ followed by 10 min wash in standard PSS.

477 To evaluate cell death (14), fluorescent images of nuclear staining with Hoechst

47833342 and propidium iodide were acquired with appropriate filters using a 40X water

479 immersion objective $(N A=0.8)$ coupled to a DS-Qi2 camera with Elements software 480 (version 4.51) on an E800 microscope (Nikon). Z-stacks were acquired from the top half

481 of the vessel segment and analyzed using ImageJ software. Stained nuclei were counted

482 manually within a defined region of interest $(150 \times 500 \mu \mathrm{m}$ in intact microvessels, $50 \mathrm{x}$

$483300 \mu \mathrm{m}$ in endothelial tubes); nuclei of ECs are oval shaped and oriented parallel to the

484 vessel axis while SMC nuclei are thin and oriented perpendicular to the vessel axis (14).

485 For each cell type, cell death is expressed as a percentage as follows: (\# propidium 486 iodide ${ }^{+}$nuclei / \# Hoechst $33342^{+}$nuclei) $\times 100$.

Muscle injury by local injection of $\mathrm{BaCl}_{2}$

A mouse was anesthetized with ketamine + xylazine and rested on an aluminum

491 and sterilized by wiping with Betadine Solution (Purdue Products LP; Stamford, CT, USA)

492 followed by $70 \%$ alcohol. An incision $(\sim 5 \mathrm{~mm})$ was made through the skin to expose the

493 gluteus maximus muscle (GM) near the lumbar fascia. Using a Hamilton syringe and 32

494 gauge needle (Reno, NV, USA), $75 \mu \mathrm{L}$ of $1.2 \% \mathrm{BaCl}_{2}$ in water was injected under the GM

495 to injure the muscle (9). The incision was closed with surgical glue or two discontinuous

496 sutures. The mouse was placed on a heated platform, monitored until consciousness and 
497 ambulation were restored, then returned to its original cage. Mice routinely recovered

498 normal activity and behavior within $24 \mathrm{~h}$ and were studied up to $21 \mathrm{dpi}$ with uninjured mice

499 (0 dpi) serving as controls. The $21 \mathrm{dpi}$ time point coincides with recovery of vasomotor

500 control in arteriolar networks and restoration of myofiber number during regeneration of

501 the mouse GM following $\mathrm{BaCl}_{2}$ injury (9).

502

503 Neutrophil depletion

504 Inflammation is integral to muscle injury (20). In some experiments, neutrophils

505 were depleted prior to $\mathrm{BaCl}_{2}$ injection using a neutralizing Ly6G antibody. Mice were

506 injected intraperitoneally with either $500 \mu \mathrm{g}$ of anti-Ly6G 1A8 antibody [\#BE0075,

507 BioxCell; Lebanon, NH, USA; (59)] or vehicle (sterile saline) on -2, -1, and 0 dpi.

508 Neutrophil depletion was confirmed by a differential blood count of a sample collected by

509 cardiac puncture in mice anesthetized with ketamine + xylazine. A drop of whole blood

510 was spread on a glass slide and stained with a Wright Giemsa stain. Leukocytes were

511 counted in sets of 100 cells, differentiating between lymphocytes, neutrophils, and

512 monocytes. Two sets of 100 counts were averaged per slide. Blood samples were

513 obtained from mice without muscle injury ( $0 \mathrm{dpi}$ ) and at $1 \mathrm{dpi}$ and compared to mice

514 injected with the vehicle at the same time points.

516 Dissection of gluteus maximus muscle

517 A mouse was anesthetized with ketamine + xylazine as above. Supplemental

518 doses ( $20 \%$ of initial dose) were given (intraperitoneal injection) throughout the

519 experimental protocol (typically lasting 2-3 h) to maintain a stable plane of anesthesia 
520 (checked every 15 minutes by lack of withdrawal to tail or toe pinch). Hair was removed

521 by shaving and the mouse was placed on a warming plate. As previously described (60),

522 skin and connective tissue overlying the GM were removed using microdissection to

523 expose the GM. Once exposed, the GM was continuously superfused with a bicarbonate-

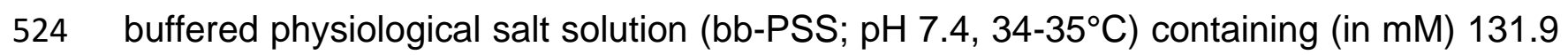

$525 \mathrm{NaCl}_{2}$ (Fisher), $4.7 \mathrm{KCl}$ (Fisher), $2 \mathrm{CaCl}_{2}$ (Sigma), $1.17 \mathrm{MgSO}_{4}$ (Sigma), and $18 \mathrm{NaHCO}_{3}$

526 (Sigma) equilibrated with $5 \% \mathrm{CO}_{2} / 95 \% \mathrm{~N}_{2}$. While viewing through a stereomicroscope,

527 the GM was cut along its origin from the lumbar fascia, sacrum, and iliac crest to reflect

528 the muscle away from the body and reveal its vascular supply on the ventral side. The

529 muscle was then either removed for immunostaining or prepared for intravital microscopy

530 as described below.

531

532 Whole mount immunostaining for confocal imaging

533 The GM from C57BL/6J mice was excised, placed in ice-cold phosphate buffered

534 saline (PBS, pH 7.4; \#P3813, Sigma) and placed onto transparent rubber coated 12 well

535 plate. The muscle was spread to approximate its dimensions in situ with the ventral

536 surface facing up and secured at the edges with insect pins. Excessive connective tissue

537 and fat were removed using microdissection. The GM was fixed overnight at $4{ }^{\circ} \mathrm{C}$ in $4 \%$

538 paraformaldehyde in PBS. After washing in PBS ( $3 \times 5 \mathrm{~min})$, the muscle was immersed

539 in blocking buffer containing $0.5 \%$ Triton $x-100$ (\#T8787, Sigma), $2 \%$ bovine serum

540 albumin (\#BP671; Fisher), and 4\% normal goat serum (\#50197Z, Sigma) in PBS. To

541 identify SMCs, the GM was stained with monoclonal rabbit anti-Myh11 [1:500;

542 \#ab124679; Abcam, Cambridge, UK; (61)] in blocking buffer overnight at $4^{\circ} \mathrm{C}$, then 
543 washed with blocking buffer ( $3 \times 5 \mathrm{~min})$, incubated with goat anti-rabbit Alexa 633 (1:200;

544 \#A21071, Fisher) in blocking buffer for $2 \mathrm{~h}$ at room temperature, and washed in PBS (3 $\mathrm{x}$

$54510 \mathrm{~min})$.

546 An immunostained GM was placed in a custom imaging chamber with the ventral

547 surface facing the objective to optimize resolution of the microvasculature. A small volume

548 of PBS $(<10 \mu \mathrm{L})$ was added to the chamber and the GM was flattened by placing a glass

549 block $(2 \mathrm{~cm} \times 2.5 \mathrm{~cm} \times 1 \mathrm{~cm}$; mass, $7.8 \mathrm{~g})$ on the dorsal surface. Images of the

550 microvasculature were acquired with a 10X objective (NA $=0.4$; image size, $1162.5 \mu \mathrm{m} x$

$5511162.5 \mu \mathrm{m})$ or $25 \mathrm{X}$ water immersion objective (NA $=0.95$; image size, $465 \mu \mathrm{m} \times 465 \mu \mathrm{m})$

552 on a laser scanning confocal microscope (TCS SP8, Leica Microsystems; Buffalo Grove,

553 IL) using Leica LASX software. Images were digitally rotated such that myofibers were

554 aligned vertically for analysis of capillary orientation. Maximum projection z-stacks (z-

555 step, $2 \mu \mathrm{m} ; ~ 150 \mu \mathrm{m}$ thick) were used to resolve SMC coverage and capillary network

556 morphology ( $n=4-5$ mice, 5-12 images across mice).

558 Analysis of capillary diameter and network morphology

$559 \quad$ Male Cdh5-mTmG mice expressing green fluorescent protein (eGFP) in ECs were

560 used to analyze capillary diameters and network morphology during regeneration. The

561 GM was excised, cleaned, and imaged as described above, but without prior fixation. To

562 measure the average diameter of capillaries from confocal z-stacks (image size, $465 \mu \mathrm{m}$

$563 \times 465 \mu \mathrm{m})$, a calibrated $5 \times 5$ grid was centered over the image, creating 25 equal ROls

$564(93 \mu \mathrm{m} \times 93 \mu \mathrm{m})$. The diameter of 5 capillaries were measured manually from 10 of 25

565 ROls selected at random; these 50 measurements were averaged for the image with 2-3 
566 images analyzed per muscle from 4-6 mice. To analyze capillary network morphology

567 using ImageJ, a threshold was applied to maximum projections of z-stacks to generate a

568 binary image. The \% vascular area (area fraction) was calculated by determining the area

569 occupied by eGFP fluorescence within the entire image (465 $\mu \mathrm{m} \times 465 \mu \mathrm{m})$.

$570 \quad$ To assess capillary network morphology from a larger field of view $(1162.5 \mu \mathrm{m} x$

$5711162.5 \mu \mathrm{m})$, the binary image was skeletonized and analyzed with the Analyze Skeleton

572 plugin (ImageJ). Outputs included: \# segments, length of segments, \# connected

573 segments, and \# branch points. Segments included in this analysis contained at least 3

574 continuous pixels, which corresponded to $\sim 2.5 \mu \mathrm{m}$.

575 To calculate the continuous capillary length as a measure of fragmentation at 1

$576 \mathrm{dpi}$, the length of connected segments was summed for each network, defined as a group

577 of connected capillaries, and the maximum continuous capillary length determined for a

578 single image $(465 \mu \mathrm{m} \times 465 \mu \mathrm{m})$; the mean \pm SE of all images $(n=4-8$ images from 4

579 mice) are reported. Branch point frequency was calculated as the number of branch

580 points per total microvascular length $(\mathrm{mm})$ for a given image. The OrientationJ plugin

581 generated distribution histograms for capillary orientation analysis with $-90^{\circ}$ and $+90^{\circ}$ on

582 the horizontal axis. All measurements in Image J were validated using reference networks

583 created with known area, length, number of branch points, and orientation.

584

585 Intravital microscopy

586 The GM of anesthetized C57BL/6J mice was dissected as described above, then

587 spread onto a transparent rubber pedestal and pinned at its edges to approximate in situ

588 dimensions $(9,60)$. The preparation was transferred to the stage of a Nikon E600FN 
589 microscope and equilibrated for 30 min while continuously superfused with bb-PSS at 3

$590 \mathrm{~mL} / \mathrm{min}$ maintained at $34-35^{\circ} \mathrm{C}(\mathrm{pH}, 7.4)$. To assess vascular perfusion and permeability

591 during maximum capillary damage (1 dpi), a fluorescein isothiocyanate (FITC) conjugated

592 dextran (70 kDa, to approximate the mass of albumin) was injected into the retro-orbital

593 sinus to access the systemic circulation and allowed to circulate for $\sim 10 \mathrm{~min}$. The

594 preparation was illuminated by a mercury lamp for fluorescence imaging using

595 appropriate filters. Images were acquired through a 4X objective (Nikon Fluor4; NA = 0.1;

596 image size, $2.7 \mathrm{~mm} \times 3.4 \mathrm{~mm}$ ) coupled to a low light CMOS FP-Lucy camera (Stanford

597 Photonics; Palo Alto, CA, USA) and displayed on a digital monitor. Time lapse images

598 were recorded at 40 frames/s using Piper Control software (Stanford Photonics). At the

599 end of the experiment, the mouse was given an overdose of anesthetic and killed by

600 cervical dislocation.

601

602

Mapping arteriolar networks

603

In anesthetized mice, wheat germ agglutinin conjugated to Alexa Fluor 647 (WGA-

$604647,1 \mathrm{mg} / \mathrm{mL}, 200 \mu \mathrm{L}$; \#W32466, Fisher) was injected into the retroorbital sinus to access

605 the systemic circulation and label the endothelial glycocalyx. The WGA-647 distributed

606 throughout the vascular compartment for $10 \mathrm{~min}$. Thereafter, the GM was dissected,

607 cleaned, and secured with pins as above. The GM was fixed overnight at $4^{\circ} \mathrm{C}(4 \%$

608 paraformaldehyde in PBS) avoiding direct light. Tissues were washed in PBS, cleared in

$609100 \%$ glycerol overnight at $4^{\circ} \mathrm{C}$, then rinsed in PBS, mounted onto a slide, and

610 coverslipped. 
Whole mount GM preparations were viewed using a Nikon Eclipse 600 microscope

612 with a Nikon Plan Fluor 10X objective (NA 0.3) coupled to a CMOS camera (Orca Flash

613 4.0; Hamamatsu) and personal computer. The XYZ translational stage (Ludl Electronic,

614 Hawthorne, NY, USA) was controlled by stepper motors coupled to an integrated joystick

615 for constant repositioning of the tissue during imaging. The tracing icon was adjusted by

616 the operator to match vessel diameter; spatial resolution was $<2 \mu \mathrm{m}$. This strategy is

617 similar to that used in aged mice (60). A grid slide (MBF Bioscience; Williston, VT) was

618 used for parcentric and parfocal calibration when linking the hardware with the software.

619 A stage micrometer ( $100 \times 0.01=1 \mathrm{~mm}$; Graticules Ltd, Tonbridge Kent, UK) validated

620 the calibration.

621

$6223 D$ reconstruction and analysis of resistance networks

623 Vesselucida Microscope Edition software (MBF Bioscience) was used to trace

624 entire resistance networks in the GM, from the inferior gluteal (feed) artery to terminal

625 arterioles. Some tracings contained collateral branches to the resistance network fed by

626 the superior gluteal artery. Occasionally, in thicker regions of the GM, reduced visibility

627 resulted in discontinuous or incomplete networks, which were not used in the present

628 analyses. Furthermore, for criterion data, networks containing fewer than 100 vessel

629 segments in the completed tracing were excluded from analyses. Vesselucida Explorer

630 software (MBF Bioscience) was used to calculate \# segments, diameter, length, and \# of

631 anastomoses in each tracing. To generate summary histograms across GM preparations

632 during regeneration, segments were binned into diameter increments of $1 \mu \mathrm{m}$; for 
633 cumulative length, those within each bin were summed. Anastomoses were defined as

634 the shortest length to return to a given branch point.

635

\section{Statistics}

637 Statistical analyses were performed using Prism 9 software (GraphPad Software 638 Inc., La Jolla, CA, USA). For in vitro experiments of isolated vessel preparations, $V_{m}$,

$639\left[\mathrm{Ca}^{2+}\right] \mathrm{i}$, and diameter were analyzed with a paired two-tailed Student's t-test. For capillary

640 network morphology, variables evaluated during regeneration were analyzed by 1-way

641 ANOVA and Tukey's multiple comparisons post-hoc test. Frequency distributions for

642 dimensions of resistance networks were analyzed with a Kolmogorov-Smirnov test. P <

6430.05 was considered statistically significant. Values for $\mathrm{n}$ given in figure captions refer to 644 the number of vessels or images evaluated from 4-6 mice.

\section{Acknowledgements}

647 The authors thank Dr. Robert Arpke for performing tamoxifen injections for Cdh5-

$648 \mathrm{mTmG}$ mice. Dr. Erika Boerman provided use of her confocal microscope for imaging 649 capillary network morphology. Dr. Susan Tappan and Timothy Tetreault at MBF 650 Bioscience provided expert technical assistance with applying Vesselucida software to 651 our analyses of arteriolar networks.

652

\section{Additional Information}

654 Competing interests

655 The authors declare that no competing interests exist. 


\begin{tabular}{l|l|l}
\hline Funder & Grant reference number & Author \\
\hline $\begin{array}{l}\text { University of Missouri, School of } \\
\text { Medicine }\end{array}$ & $\begin{array}{l}\text { Margaret Proctor Mulligan } \\
\text { Endowed Professorship } \\
\text { Margaret Proctor Mulligan } \\
\text { Fellowship }\end{array}$ & Steven S. Segal \\
\hline $\begin{array}{l}\text { University of Missouri, School of } \\
\text { Medicine }\end{array}$ & Development Award & Steven S. Segal \\
\hline National Institutes of Health & R37 HL-041026 & Steven S. Segal \\
\hline National Institutes of Health & F32 HL-152558 & Nicole L. Jacobsen \\
\hline National Institutes of Health & R01 AR-067450 & DDW Cornelison \\
\hline
\end{tabular}

The funders had no role in study design, data collection and interpretation, or the decision to submit the work for publication.

\section{8}

659

660

661

662

663

664

665

666

\section{Author Contributions}

NL Jacobsen: Conceptualization, Data Curation, Formal Analysis, Validation, Investigation, Methodology, Funding Acquisition, Writing-original draft, Writing-review and editing; CN Norton: Data Curation, Formal Analysis, Validation, Investigation, Methodology, Writing-review and editing; RL Shaw: Data Curation, Investigation, Methodology, Writing-review and editing; DDW Cornelison: Conceptualization, Supervision, Funding Acquisition, Resources, Writing-review and editing; SS Segal: Conceptualization, Data Curation, Supervision, Methodology, Funding Acquisition, Resources, Writing-review and editing, Project Administration. 


\section{References}

668 1. Yin H, Price F, and Rudnicki MA. Satellite cells and the muscle stem cell niche.

669 Physiol Rev 93: 23-67, 2013.

670 2. Karalaki M, Fili S, Philippou A, and Koutsilieris M. Muscle regeneration: cellular 671 and molecular events. In Vivo 23: 779-796, 2009.

672 3. Segal SS. Regulation of blood flow in the microcirculation. Microcirculation 12: 33$673 \quad 45,2005$.

674 4. Segal SS and Duling BR. Communication between feed arteries and 675 microvessels in hamster striated muscle: Segmental vascular responses are functionally 676 coordinated. Circ Res 59: 283-290, 1986.

677 5. Olfert IM, Breen EC, Mathieu-Costello O, and Wagner PD. Skeletal muscle 678 capillarity and angiogenic mRNA levels after exercise training in normoxia and chronic 679 hypoxia. J Appl Physiol (1985) 91: 1176-1184, 2001.

680 6. Peirce SM and Skalak TC. Microvascular remodeling: a complex continuum 681 spanning angiogenesis to arteriogenesis. Microcirculation 10: 99-111, 2003.

682 7. Hardy D, Besnard A, Latil M, Jouvion G, Briand D, Thepenier C, Pascal Q, 683 Guguin A, Gayraud-Morel B, Cavaillon JM, Tajbakhsh S, Rocheteau P, and Chretien 684 F. Comparative study of injury models for studying muscle regeneration in mice. PLoS 685 One 11: e0147198, 2016.

686 8. Morton AB, Norton CE, Jacobsen NL, Fernando CA, Cornelison DDW, and 687 Segal SS. Barium chloride injures myofibers through calcium-induced proteolysis with 688 fragmentation of motor nerves and microvessels. Skelet Muscle 9: 27, 2019. 
689 9. Fernando CA, Pangan AM, Cornelison D, and Segal SS. Recovery of blood flow 690 regulation in microvascular resistance networks during regeneration of mouse gluteus 691 maximus muscle. J Physiol 597: 1401-1417, 2019.

692 10. Arpino JM, Nong Z, Li F, Yin H, Ghonaim N, Milkovich S, Balint B, O'Neil C,

693 Fraser GM, Goldman D, Ellis CG, and Pickering JG. Four-dimensional microvascular 694 analysis reveals that regenerative angiogenesis in ischemic muscle produces a flawed 695 microcirculation. Circ Res 120: 1453-1465, 2017.

696 11. Socha MJ and Segal SS. Isolation of microvascular endothelial tubes from mouse 697 resistance arteries. J Vis Exp: e50759, 2013.

698 12. Lipscombe D, Helton TD, and Xu W. L-type calcium channels: the low down. J 699 Neurophysio/ 92: 2633-2641, 2004.

700 13. Moccia F, Berra-Romani R, and Tanzi F. Update on vascular endothelial $\mathrm{Ca}^{(2+)}$ 701 signalling: A tale of ion channels, pumps and transporters. World J Biol Chem 3: 127-158, 7022012.

703 14. Norton CE, Sinkler SY, Jacobsen NL, and Segal SS. Advanced age protects 704 resistance arteries of mouse skeletal muscle from oxidative stress through attenuating 705 apoptosis induced by hydrogen peroxide. J Physiol 597: 3801-3816, 2019.

706 15. Norton CE, Jacobsen NL, Sinkler SY, Manrique-Acevedo C, and Segal SS. 707 Female sex and Western-style diet protect mouse resistance arteries during acute 708 oxidative stress. Am J Physiol Cell Physiol 318: C627-C639, 2020.

709 16. Norton CE and Segal SS. Calcitonin gene-related peptide hyperpolarizes mouse 710 pulmonary artery endothelial tubes through K(ATP) channel activation. Am J Physiol Lung 711 Cell Mol Physiol 315: L212-L226, 2018. 
712 17. Babu GJ, Warshaw DM, and Periasamy M. Smooth muscle myosin heavy chain

713 isoforms and their role in muscle physiology. Microsc Res Tech 50: 532-540, 2000.

714 18. Miano JM, Cserjesi P, Ligon KL, Periasamy M, and Olson EN. Smooth muscle 715 myosin heavy chain exclusively marks the smooth muscle lineage during mouse 716 embryogenesis. Circ Res 75: 803-812, 1994.

717 19. Fielding RA, Manfredi TJ, Ding W, Fiatarone MA, Evans WJ, and Cannon JG. 718 Acute phase response in exercise. III. Neutrophil and IL-1 beta accumulation in skeletal 719 muscle. Am J Physiol Regul Integr Comp Physiol 265: R166-R172, 1993.

72020 . Tidball JG. Regulation of muscle growth and regeneration by the immune system.

721 Nature Reviews Immunology 17: 165-178, 2017.

722 21. Wang Y, Nakayama M, Pitulescu ME, Schmidt TS, Bochenek ML, Sakakibara

723 A, Adams S, Davy A, Deutsch U, Luthi U, Barberis A, Benjamin LE, Makinen T,

724 Nobes CD, and Adams RH. Ephrin-B2 controls VEGF-induced angiogenesis and 725 lymphangiogenesis. Nature 465: 483-486, 2010.

726 22. Risau W and Flamme I. Vasculogenesis. Annu Rev Cell Dev Biol 11: 73-91, 1995.

727 23. Emerson GG and Segal SS. Alignment of microvascular units along skeletal 728 muscle fibers of hamster retractor. J Appl Physiol 82: 42-48, 1997.

729 24. Rubenstein AB, Smith GR, Raue U, Begue G, Minchev K, Ruf-Zamojski F, Nair 730 VD, Wang X, Zhou L, Zaslavsky E, Trappe TA, Trappe S, and Sealfon SC. Single-cell

731 transcriptional profiles in human skeletal muscle. Scientific Reports 10: 229, 2020.

732 25. Bonev AD and Nelson MT. ATP-sensitive potassium channels in smooth muscle 733 cells from guinea pig urinary bladder. Am J Physiol 264: C1190-C1200, 1993. 
734 26. Nelson MT and Quayle JM. Physiological roles and properties of potassium

735 channels in arterial smooth muscle. Am J Physiol 268: C799-C822, 1995.

736 27. Pinton P, Giorgi C, Siviero R, Zecchini E, and Rizzuto R. Calcium and

737 apoptosis: ER-mitochondria $\mathrm{Ca}^{2+}$ transfer in the control of apoptosis. Oncogene 27: 6407-

$7386418,2008$.

739 28. Karaki H, Satake N, and Shibata S. Mechanism of barium-induced contraction in

740 the vascular smooth muscle of rabbit aorta. Br J Pharmacol 88: 821-826, 1986.

741 29. Park SY, Gifford JR, Andtbacka RH, Trinity JD, Hyngstrom JR, Garten RS,

742 Diakos NA, Ives SJ, Dela F, Larsen S, Drakos S, and Richardson RS. Cardiac,

743 skeletal, and smooth muscle mitochondrial respiration: are all mitochondria created

744 equal? Am J Physiol Heart Circ Physiol 307: H346-352, 2014.

745 30. Cho $\mathbf{C H}$, Woo JS, Perez CF, and Lee EH. A focus on extracellular $\mathrm{Ca}^{(2+)}$ entry 746 into skeletal muscle. Exp Mol Med 49: e378, 2017.

747 31. Silvis MJM, Kaffka Genaamd Dengler SE, Odille CA, Mishra M, van der Kaaij

748 NP, Doevendans PA, Sluijter JPG, de Kleijn DPV, de Jager SCA, Bosch L, and van

749 Hout GPJ. Damage-associated molecular patterns in myocardial infarction and heart

750 transplantation: the road to translational success. Front Immunol 11: 599511, 2020.

751 32. Clanton TL. Hypoxia-induced reactive oxygen species formation in skeletal

752 muscle. J Appl Physiol (1985) 102: 2379-2388, 2007.

753 33. Zhang Y, Liu NM, Wang Y, Youn JY, and Cai H. Endothelial cell calpain as a

754 critical modulator of angiogenesis. Biochim Biophys Acta Mol Basis Dis 1863: 1326-1335, 7552017. 
756 34. Diez-Roux G and Lang RA. Macrophages induce apoptosis in normal cells in 757 vivo. Development 124: 3633-3638, 1997.

$758 \quad 35 . \quad$ Luque E, Pena J, Martin P, Jimena I, and Vaamonde R. Capillary supply during 759 development of individual regenerating muscle fibers. Anat Histol Embryol 24: 87-89, 7601995.

761 36. Skalak TC and Schmid-Schönbein GW. The microvasculature in skeletal 762 muscle. IV. A model of the capillary network. Microvasc Res 32: 333-347, 1986.

763 37. Krock BL, Skuli N, and Simon MC. Hypoxia-induced angiogenesis: good and 764 evil. Genes Cancer 2: 1117-1133, 2011.

765 38. Blanco R and Gerhardt H. VEGF and Notch in tip and stalk cell selection. Cold 766 Spring Harbor Perspectives in Medicine 3: a006569, 2013.

767 39. Ziche M and Morbidelli L. Nitric oxide and angiogenesis. J Neurooncol 50: 139$768148,2000$.

769 40. McGahren ED, Beach JM, and Duling BR. Capillaries demonstrate changes in

770 membrane potential in response to pharmacological stimuli. Am J Physiol 274: H60-H65, 7711998.

772 41. Hamilton NB, Attwell D, and Hall CN. Pericyte-mediated regulation of capillary 773 diameter: a component of neurovascular coupling in health and disease. Front 774 Neuroenergetics 2, 2010.

775 42. Peppiatt CM, Howarth C, Mobbs P, and Attwell D. Bidirectional control of CNS 776 capillary diameter by pericytes. Nature 443: 700-704, 2006.

777 43. Aird WC. Endothelial cell heterogeneity. Cold Spring Harbor Perspectives in 778 Medicine 2: a006429, 2012. 
779 44. Jambusaria A, Hong Z, Zhang L, Srivastava S, Jana A, Toth PT, Dai Y, Malik

$780 \mathrm{AB}$, and Rehman J. Endothelial heterogeneity across distinct vascular beds during

781 homeostasis and inflammation. Elife 9, 2020.

782 45. Badr I, Brown MD, Egginton S, Hudlická O, Milkiewicz M, and Verhaeg J.

783 Differences in local environment determine the site of physiological angiogenesis in rat

784 skeletal muscle. Exp Physiol 88: 565-568, 2003.

785 46. Deveci D, Marshall JM, and Egginton S. Relationship between capillary 786 angiogenesis, fiber type, and fiber size in chronic systemic hypoxia. Am J Physiol Heart

787 Circ Physiol 281: H241-H252, 2001.

788 47. Lampa SJ, Potluri S, Norton AS, and Laskowski MB. A morphological technique 789 for exploring neuromuscular topography expressed in the mouse gluteus maximus 790 muscle. Journal of Neuroscience Methods 138: 51-56, 2004.

791 48. Rakusan $\mathrm{K}$ and Turek $\mathbf{Z}$. The effect of heterogeneity of capillary spacing and $\mathrm{O}_{2}$ 792 consumption--blood flow mismatching on myocardial oxygenation. Adv Exp Med Biol 191: $793 \quad 257-262,1985$.

794 49. Degens H, Deveci D, Botto-van Bemden A, Hoofd LJ, and Egginton S. 795 Maintenance of heterogeneity of capillary spacing is essential for adequate oxygenation 796 in the soleus muscle of the growing rat. Microcirculation 13: 467-476, 2006.

797 50. Messina LM and Carlson BM. Rapid and complete recovery of responsiveness 798 to adenosine and norepinephrine by regenerating arterioles of the tibialis anterior muscle 799 of the hamster after in situ autografting. Circ Res 68: 1600-1609, 1991.

800 51. Mancuso MR, Davis R, Norberg SM, O'Brien S, Sennino B, Nakahara T, Yao 801 VJ, Inai T, Brooks P, Freimark B, Shalinsky DR, Hu-Lowe DD, and McDonald DM. 
802 Rapid vascular regrowth in tumors after reversal of VEGF inhibition. J Clin Invest 116: $803 \quad 2610-2621,2006$.

804 52. Kelly-Goss MR, Sweat RS, Azimi MS, and Murfee WL. Vascular islands during 805 microvascular regression and regrowth in adult networks. Front Physiol 4: 108, 2013.

806 53. Hansen-Smith FM. Capillary network patterning during angiogenesis. Clin Exp 807 Pharmacol Physiol 27: 830-835, 2000.

808 54. Hansen-Smith FM, Carlson BM, and Irwin KL. Revascularization of the freely 809 grafted extensor digitorum longus muscle in the rat. Am J Anat 158: 65-82, 1980.

810 55. Vracko R and Benditt EP. Basal lamina: the scaffold for orderly cell replacement.

811 Observations on regeneration of injured skeletal muscle fibers and capillaries. The 812 Journal of Cell Biology 55: 406-419, 1972.

813 56. Bailey AM, O'Neill TJt, Morris CE, and Peirce SM. Arteriolar remodeling

814 following ischemic injury extends from capillary to large arteriole in the microcirculation.

815 Microcirculation 15: 389-404, 2008.

816 57. Mac Gabhann F and Peirce SM. Collateral capillary arterialization following

817 arteriolar ligation in murine skeletal muscle. Microcirculation 17: 333-347, 2010.

818 58. Socha MJ, Hakim CH, Jackson WF, and Segal SS. Temperature effects on 819 morphological integrity and $\mathrm{Ca}^{2+}$ signaling in freshly isolated murine feed artery 820 endothelial cell tubes. Am J Physiol Heart Circ Physiol 301: H773-H783, 2011.

821 59. Bamboat ZM, Ocuin LM, Balachandran VP, Obaid H, Plitas G, and DeMatteo 822 RP. Conventional DCs reduce liver ischemia/reperfusion injury in mice via IL-10 823 secretion. J Clin Invest 120: 559-569, 2010. 
824 60. Bearden SE, Payne GW, Chisty A, and Segal SS. Arteriolar network architecture

825 and vasomotor function with ageing in mouse gluteus maximus muscle. J Physiol 561:

$826 \quad 535-545,2004$.

827 61. Duivenvoorden HM, Spurling A, O'Toole SA, and Parker BS. Discriminating the 828 earliest stages of mammary carcinoma using myoepithelial and proliferative markers.

$829 \quad$ PLoS One 13: e0201370, 2018. 